\title{
Some Reflections on Reforms of the Graduate Education System in China
}

\author{
Qingliang Chen, Yi Zhen \\ College of Information Science and Technology, Jinan University, Guangzhou 510632, China \\ zhenyi0609@126.com
}

\begin{abstract}
The graduate education in China plays a more and more important role nowadays, as the industries around the country are striving to strengthen their international competitiveness, which needs more and more advanced and talented labor force accordingly. However, the current graduate education system in China can not meet the change above and thus needs reforms and improvement. In this paper, based on the current circumstances in China, we provide some reflections on how to enhance and lubricate the system, by referencing the ones in developed countries like the United States, the United Kingdom, Germany and Japan.
\end{abstract}

Index Terms - Graduate education system, reforms

\section{Introduction}

After more than 30 years of development, the graduate education system in China has overtaken the United States and become the largest in the world since 2009, as far as the number of enrollment is concerned [1]. The trend of increase is especially evident during the past ten years, which can be illustrated by the following Fig.1:

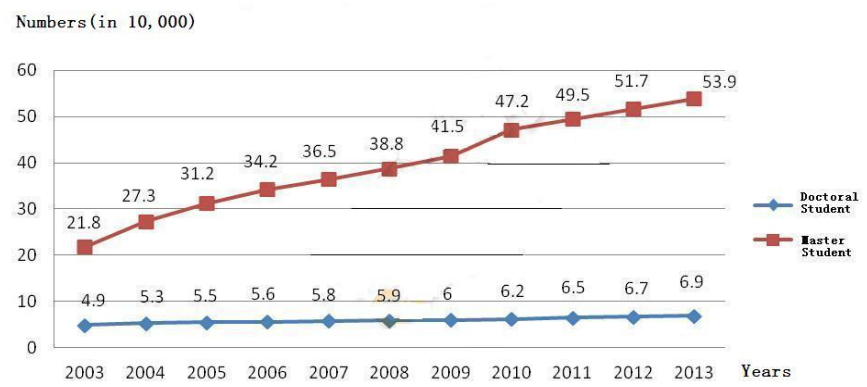

Fig.1. The number of graduate students enrolled in China from 2003-2013

However, this dramatic increase in numbers of graduate students does not promote China's ranking in Global Competitiveness Index (GCI) too much, which is an indicator defined by the World Economic Forum to assess the drivers of an economy's productivity and prosperity [2]. As the following table shows, we can see that China's ranking in GCI only moves up to the 29th in 2013 from the 44th in 2003, which implies that our graduate education system fails to a certain extent to produce advanced and well-qualified labor force to build up the competitiveness of the country.
TABLE I The GCI of China in 2003 and 2013

\begin{tabular}{|c|c|c|c|c|}
\hline & \multicolumn{2}{|c|}{ GCI 2003 Rank } & \multicolumn{2}{|c|}{ GCI 2002 Rank } \\
\hline Country & $\begin{array}{c}\text { (among } 2003 \\
\text { countries) }\end{array}$ & $\begin{array}{l}\text { (among } 2002 \\
\text { countries) }\end{array}$ & (revised*) & (original) \\
\hline Finland & 1 & 1 & 1 & 2 \\
\hline United States & 2 & 2 & 2 & 1 \\
\hline Sweden & 3 & 3 & 3 & 5 \\
\hline South Africa & 42 & 40 & 34 & 32 \\
\hline Slovak Republic & 43 & 41 & 46 & 49 \\
\hline \multirow[t]{2}{*}{ China } & 44 & 42 & 38 & 33 \\
\hline & \multicolumn{3}{|c|}{ GCI 2013-2014 } & \\
\hline Country/Economy & $\begin{array}{c}\text { Rank } \\
\text { (out of 148) }\end{array}$ & $\begin{array}{l}\text { Score } \\
(1-7)\end{array}$ & $\begin{array}{l}\text { Rank among } \\
2012-2013 \\
\text { economies }\end{array}$ & $\begin{array}{c}\text { GCl } \\
2012-2013\end{array}$ \\
\hline Switzerland & 1 & 5.67 & 1 & 1 \\
\hline Singapore & 2 & 5.61 & 2 & 2 \\
\hline Finland & 3 & 5.54 & 3 & 3 \\
\hline Germany & 4 & 5.51 & 4 & 6 \\
\hline United States & 5 & 5.48 & 5 & 7 \\
\hline Israel & 27 & 4.94 & 27 & 26 \\
\hline Ireland & 28 & 4.92 & 28 & 27 \\
\hline China & 29 & 4.84 & 29 & 29 \\
\hline
\end{tabular}

Therefore, some reflections on how to enhance and lubricate the system should be addressed. In this paper, we firstly enumerate some problems in this system, and then we reference some systems in developed countries like the United States, the United Kingdom, Germany and Japan. Finally, based on the current situations of China, we give our reflections and advices on how to reform the system to meet the needs of the country.

\section{Problems in the Existing Graduate Education System}

Here, we point out some existing problems in our graduate education system:

\section{(1) Government-dominated Management}

The graduate education system is criticized for many years because of too much government interference and too less autonomy. The system is completely dominated by the government, namely, the Ministry of Education and the Academy Degree Committee in the State Council. They will decide which university can enroll graduate students along with the quota for each year; which university is dubbed "key university" and thus can receive more fiscal support and better policies, and the criteria on how to assess the universities for their performance, etc. This kind of system has some merits since the centralized control can concentrate resources to do something good. However, it can do something bad as well. What's more, because the government has so much power in controlling everything and it is the major source of money for universities, the leaders in universities have to cater for those 
government officials and even have to bribe them, leading to corruption.

\section{(2) The Enrolment System}

The current way to enroll a graduate student in universities in China is through the National Graduate Entrance Exam. And the Ministry of Education will provide a baseline of score for every discipline for enrolment. This unified and nation-wide test may seem to be fair since it is a common benchmark for every potential student. However, for a graduate student, what matters most is the ability to do innovative research, which is beyond the scope of a simple test. Furthermore, the organization, grading and matriculation process of such a nation-wide exam cost quite a lot for universities and students. Finally, students from different universities may have different knowledge structure, background and skills, it is not so appropriate to assess them in a uniform way.

\section{(3)The Education Mode}

Since 1991, the graduate education in China has been divided into two main tracks of mode: the research-oriented one and the practice-oriented one. And the latter one is attached more and more importance now because it is quite welcomed in the job market and thus increases fast. However, the distinction between the two kinds of students is not so obvious. Firstly, the matriculation is still based on the scores of the exam, and their practical skills are ignored to a certain degree. Secondly, the graduate programs for the two tracks seem to have too much in common. For example, for the practice-oriented track, students should be provided internship in related industries for a certain period of time and even should be allowed to finish their dissertations there (accordingly, the dissertation committee should include members from the industries). However, very few universities can provide such an opportunity for students.

\section{(4)Financial Support System}

Graduate students should be well supported financially to do researches and live a normal life. However, the financial support system in universities in China fails to serve that purpose. For example, the current policy to use research funds only allocates a very small portion (usually 15\%) to recruit graduate students to be research assistants, which is far from enough. And a large portion of them is reserved for other unnecessary purposes that can be considered as a waste. Therefore, professors have to find other ways to support their students to cover their daily maintenance. Meanwhile, the process of reimbursement from the research funds is quite tedious and time-consuming, featured by bureaucratic jungles. Both professors and students have to take a lot of time on how to spend the money to get things done in a permissible fashion.

\section{Graduate Education Systems in Developed Countries}

In this section, we showcase the graduate education systems in some developed countries and see how we can be inspired to reform our own.

\section{(1) The United States}

The graduate education system in US is undoubtedly one of the best in the world, featured by its best quality and highly autonomy even in public universities. The government only establishes some macro policies and seldom involves in the micro issues in graduate education and thus the universities run like an autonomous community somehow [3].

The system also enjoys multiple sources of investment, some from the federal government, some from the state, and some from donations of the foundations and companies, etc. So they have enough resources to support their students in different ways, including fellowship, research assistantship and teaching assistantship, etc. And at least $50 \%$ of their research funds can be used to pay for those kinds of support.

As for the enrolment, the system does not have a national exam. It only adopts some standard test from ETS such as GRE and GMAT. Every university can set up their own criteria to enrol a student, based on their recommendation letters, academic records and GPA, etc. Once they are enrolled, they will be provided quite flexible graduate programs, along with a high standard to get a degree. Those graduate programs usually go beyond campuses, because the research exchange with the outside is quite often, and students always have a lot of chances to visit or intern in other research institutes and industries. Therefore, the graduated students can soon meet the needs of the society.

\section{(2) The United Kingdom}

The current graduate education system in UK is the product of the reform in the 1990s [4]. It is managed by the central and local government. However, they also enjoy highly autonomy like their peers in the US. So each university has its own way to enrol students and design their specific graduate programs.

As for their education mode, master students concentrates mainly in their courses while doctoral students mainly in researches. At the same time, the system has set up strict rules which the students need to pass before they get the corresponding degree. Also they have permissible durations for the length of the studies. For example, no more than 2 years for full-time MPhil student (research-oriented master students), 3 years for full-time doctoral students and 5 years for part-time ones.

The financial support system is also comprehensive, like governmental loans such as Tuition loan and Maintenance loan, scholarship such as Chevening Scholarship from the Ministry of Foreign Affairs, and many kinds of subsidies to support part-time jobs for students such as Hardship Awards of the Board of Graduate Studies.

\section{(3) Germany}

Unlike US and UK, Germany does not have private universities. However, the graduate education system also grants the universities great autonomy, or more precisely, the professors. The system in Germany can be characterized as "apprentice-style led by professors", because professors have 
been vested with absolute power in deciding major issues such as enrolment, financial support and graduation criteria [5].

The apprentice-style mode of education means that the students must join the research project led by their professors. And those professors will supervise and guide them throughout the project. The students will be trained well in this way on how to do research, theoretically or practically. And their contribution to this project will be summarized as their dissertations.

The financial support system is diversified as well.

The most notable one is DAAD (Deutscher Akademischer Austausch Dienst) [6], a government-funded institute for academy research providing scholarship like Study Scholarship, Research Grant and Research Internships in Science and Engineering Scholarship. In addition to DAAD, there are a lot of foundations in Germany providing those kinds of support such as Alexander von Humboldt Foundation and Konrad Adenauer Foundation.

\section{(4) Japan}

The graduate education system in Japan shares something in common with that of UK. It is managed by both the central and local government, but the central one has more powers and the universities have less autonomy compared with their western counterparts [7]. But since 2003, the Japanese government has kick-started a reform and gives more and more autonomy to the universities. In recent years, the money from the government occupies only $50 \%-60 \%$ of the total budget of the universities.

As for the enrolment, there is no national exam. Every university and institution has their own graduate entrance exam, which may include some tests like foreign languages, professional skills and analytical think, and may be held in different dates and frequency.

The most important feature of the graduate education system in Japan is its close incorporation with the industries. The universities, research institutes and the research laboratories in industries work closely to provide platforms, equipments, expertise and professional guidance for graduate students, so as to bridge the gap between theoretical researches and practical applications.

The financial support system is also comprehensive in Japan. For example, the government-funded Independent Administrative Institution Japan Student Services Organization (JASSO) is the most remarkable one which has the broadest coverage of the students (about $75 \%$ of the total students helped) [8]. What's more, there are other foundations providing different kinds of scholarship.

\section{Some Reflections on How to Reform Our System}

Based on the references of the developed countries and our own situations, we have the following reflections on how to enhance and lubricate our system:

\section{(1) The Management System}

In order to make the graduate education system function well, we need good management from the government. The central government and local government should play different roles to serve the system. The central government should focus on the legislation, long-term planning, regional coordination and policy making, while the local government should pay more attention to the operational layer such as the disbursement, examination and approval of the graduate programs and implementation of the policies made by the central government. Generally speaking, the government shall stay as the general and effective coordinator of the macro issues and stay away from the micro issues of the education, granting universities as much autonomy as possible. This is the most important lesson we learn from those of the developed countries.

As for the assessment of the graduate programs, the government can commission it to an independent and trustworthy third party, whose member can come from different classes of the society. And the public will definitely give a more appropriate and fair judgement on how adequately our graduate education system serves the society.

Furthermore, universities should try to diversify the sources of financing. In addition to appropriating funds, government should provide more and more favourable policies to encourage private money to go to the universities. Moreover, we can try the so called co-supervision mode: companies donate money to universities and provide internship for students, and the universities cultivate talented students specifically suited for the companies in return. So after theory studies in universities, students can immediately get corresponding practical training, and the company can finally have what they want, which is a win-win deal.

Finally, research funds from the government should be allocated more portions for living stipend of graduate students (routinely 50\%). And the reimbursement process should be streamlined as much as possible.

\section{(2) The Enrolment System}

To better the enrolment system, the span of the national entrance exam can be shortened to six months or even less, and the score of each one should be valid for two years or more, giving more opportunities for students. At the same time, there should be flexible graduate tests accordingly in different universities. For example, a student has passed the national entrance exam and the validation period is two years, and then in the following two years, he or she can take the graduate exams of a university or different universities many times until he or she is enrolled.

Simultaneously, professors should be granted more right in enrolling a student because the talents of a student can not be simply counted by scores. Sometimes, professors should have rights to enrol a student demonstrating remarkable ability in doing research but with low scores in exams.

\section{(3) The Education Mode}

Currently, the distinction between the research-oriented mode and practice-oriented mode is still vague in our system. As for the latter, we should revise the graduate programs badly to meet the real needs and changes from the industries. Here 
the role of the industries can never be ignored because they are our clients of the education product. Therefore, they should be invited to be part of the system, providing professional advices on how to set up the graduate courses, how to see the trend and changes of the industries and how to develop practical skills. Universities thus need to collaborate well with them and can even invite them to be co-superviser of students and join the dissertation committee. What's more, industries can provide internship for students to do practical researches. In a word, the only way to produce high-quality practice-oriented graduate students is that we integrate the resources of the universities and industries well.

As for the research-oriented track, students should be given more chances to work with other universities and institutes around the region, around the country and even around the world, to broaden their horizons, inspire and motivate new ideas.

\section{(4) Financial Support System}

There are several ways to improve our financial support systems in China.

Firstly, the central government can set up a non-profit student loan company, so that every graduate student is eligible to be provided a loan with reasonable interest if he or she is willing to. The loan can cover tuitions, rent and daily expenditure.

Secondly, the amount and coverage of the National Scholarship Program should be expanded. In addition to that, we should increase the corresponding provincial, municipal, university and even school-level scholarship, by attracting more funds from the government and from the public.
Thirdly, we should have more and more temporary job vacancies suitable for graduate students such as Teaching Assistants (TA) and Research Assistants (RA) so that they could pay for their studies by working with what they have learned.

Finally, the government should make some favourable policies for poor students. For example, their debts can be exempted if they choose to work in remote and rural areas for a certain period of time after graduation. This is a win-win deal because the students can successfully finish their studies without pressure, and the government can successfully encourage well-educated people to develop the backward areas.

\section{References}

[1] The National Education Statistics in China in 2009, the Ministry of Education, http://www.gov.cn/gzdt/2010-08/03/content_1670245.htm Aug 2010.

[2] The World Economic Forum, Global Competitiveness Report, http://www.weforum.org/issues/global-competitiveness.

[3] J. Han, "The Higher Education System and Configurations in the US," Higher Education in China, vol 12, pp. 45-51, Dec 2003.

[4] S.Machin and A.Vignoles, What's The Good Of Education? The Economics Of Education In The UK. Princeton University Press. 2005, ISBN 0691117349.

[5] X.Chen, "The Strategies and Implications of Graduation Education in Europe in Bologna Process" Journal of Graduate Education, vol 2, pp 69-72. April 2012.

[6] Deutscher Akademischer Austausch Dienst, https://www.daad.de/de/

[7] H,Christopher, Japanese Education Reform: Nakasone's Legacy, London: Routledge, 2001, ISBN 0-415-23283-X.

[8] Japan Student Services Organization, http://www.jasso.go.jp/ 